\title{
Development and evaluation of the first high-throughput SNP array for common carp (Cyprinus carpio)
}

Jian Xu', Zixia Zhao ${ }^{1}$, Xiaofeng Zhang ${ }^{2}$, Xianhu Zheng ${ }^{2}$, Jiongtang $\mathrm{Li}^{1}$, Yanliang Jiang ${ }^{1}, Y^{1}$ ouyi Kuang ${ }^{2}$, Yan Zhang ${ }^{1}$, Jianxin Feng ${ }^{3}$, Chuangju Li ${ }^{4}$, Juhua Yu ${ }^{5}$, Qiang Li ${ }^{1}$, Yuanyuan Zhu' ${ }^{1}$ Yuanyuan Liu', Peng Xu ${ }^{1,6^{*}}$ and Xiaowen Sun ${ }^{1,2^{*}}$

\begin{abstract}
Background: A large number of single nucleotide polymorphisms (SNPs) have been identified in common carp (Cyprinus carpio) but, as yet, no high-throughput genotyping platform is available for this species. C. carpio is an important aquaculture species that accounts for nearly $14 \%$ of freshwater aquaculture production worldwide. We have developed an array for C. carpio with 250,000 SNPs and evaluated its performance using samples from various strains of $C$. carpio.

Results: The SNPS used on the array were selected from two resources: the transcribed sequences from RNA-seq data of four strains of C. carpio, and the genome re-sequencing data of five strains of C. carpio. The 250,000 SNPs on the resulting array are distributed evenly across the reference C.carpio genome with an average spacing of $6.6 \mathrm{~kb}$. To evaluate the SNP array, 1,072 C. carpio samples were collected and tested. Of the 250,000 SNPs on the array, 185,150 (74.06\%) were found to be polymorphic sites. Genotyping accuracy was checked using genotyping data from a group of full-siblings and their parents, and over $99.8 \%$ of the qualified SNPs were found to be reliable. Analysis of the linkage disequilibrium on all samples and on three domestic C.carpio strains revealed that the latter had the longer haplotype blocks. We also evaluated our SNP array on 80 samples from eight species related to $C$. carpio, with from 53,526 to 71,984 polymorphic SNPs. An identity by state analysis divided all the samples into three clusters; most of the C. carpio strains formed the largest cluster.

Conclusions: The Carp SNP array described here is the first high-throughput genotyping platform for C. carpio. Our evaluation of this array indicates that it will be valuable for farmed carp and for genetic and population biology studies in C. carpio and related species.
\end{abstract}

Keywords: SNP array, Affymetrix, Re-sequencing, Linkage disequilibrium, Identity by state, Cyprinus carpio, Common carp, Cyprinidae

\section{Background}

Common carp (Cyprinus carpio) is naturally distributed across Europe and Asia. It was domesticated about 2,000 years ago, and is cultured in over 100 countries worldwide with over 3 million metric tons of global annual production [1,2]. As a result of selection and breeding efforts over the past centuries, many domesticated

\footnotetext{
* Correspondence: xupeng@cafs.ac.cn; sunxw2002@163.com

${ }^{1}$ Centre for Applied Aquatic Genomics, Chinese Academy of Fishery Sciences, Beijing 100141, China

${ }^{2}$ Heilongjiang Fisheries Research Institute, Chinese Academy of Fishery Sciences, Harbin 150070, China

Full list of author information is available at the end of the article
}

strains have been established with distinct economic traits or phenotypes adapted to local environments and to meet consumer demands. China is the largest $C$. carpio producer, and there are abundant domesticated strains and populations in China, including Sonpu mirror carp, Hebao red carp, Xingguo red carp, Yellow River carp, and Oujiang color carp, as well as many hybrid strains, all of which are the basis and genetic resources for selective breeding using modern genetic tools.

Because of the economic importance of $C$. carpio for the global aquaculture industry, as well as its importance as a model species for ecology, physiology, and evolutionary

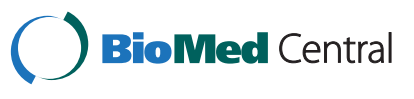

(c) 2014 Xu et al.; licensee BioMed Central Ltd. This is an Open Access article distributed under the terms of the Creative Commons Attribution License (http://creativecommons.org/licenses/by/2.0), which permits unrestricted use, distribution, and reproduction in any medium, provided the original work is properly credited. The Creative Commons Public Domain Dedication waiver (http://creativecommons.org/publicdomain/zero/1.0/) applies to the data made available in this article, unless otherwise stated. 
studies, over the past decade, researchers have developed a variety of genetic and genomics tool and resources. A large number of genetic markers have been developed, including microsatellites $[3,4]$, and single nucleotide polymorphisms (SNPs) [5,6]. A number of genetic linkage maps have been constructed based on these markers [7-10]. The markers have also been used to identify quantitative trait loci (QTLs) associated with economically important traits including growth rate, body shape, and meat quality $[4,11,12]$. A large set of expressed sequence tags (ESTs) have been generated using traditional cloning and Sanger sequencing methods, or next-generation transcriptome sequencing, and a cDNA microarray has been designed and constructed [13-17]. A bacterial artificial chromosome (BAC) library has been built [18], a BAC-based physical map has been constructed, and a large set of BAC-end sequences (BES) have been generated [19,20]. The complete mitochondrial genomes of several strains and populations have been sequenced [21-23]. Whole genome exome data were generated for a comparative study with the Danio rerio genome [24] and, recently, the $C$. carpio genome consortium has completely sequenced and assembled a draft genome sequence of C. carpio [25].

A major gap in the C. carpio toolkit is the lack of a highthroughput SNP genotyping platform for genetic research. Such a platform is essential for whole genome association studies (GWAS) of important traits, as well as for genomeassisted selection in breeding programs. Genome-scale SNP genotyping is most efficiently performed using SNP arrays or chips. Arrays of this type have been used widely in genetic studies in humans, as well as in important model organisms and agriculture species.

The reductions in the cost of acquiring sequence data using next-generation sequencing technologies has led to the development of genotyping by sequencing (GBS) approaches, which use whole genome sequencing, reduced representative genome sequencing, or target-enriched DNA sequencing data to determine genotypes. The most popular GBS protocol is restriction-site-associated DNA (RAD) tag sequencing in which DNA fragments flanking particular restriction sites are targeted for sequencing, thereby allowing the discovery and genotyping of SNPs at these targeted locations [26]. Although GBS methods have some advantages for genome-wide SNP discovery and genotyping, especially for species for which a reference genome has not been established, they also have limitations, which include the requirements for complicated DNA library preparation procedures and intensive bioinformatics pipelines. GBS is not suitable for genotyping the very large numbers of individuals or SNP loci that are used commonly in GWAS and genomic selection. In addition, GBS genotyping results are not shared easily among different research groups because the same SNP loci are not assayed in all individuals.
Therefore high-density SNP genotyping arrays remain the tools of choice for high-resolution genetics analysis. Many SNP arrays or chips have been developed for either Illumina or Affymetrix platforms, including the human $500 \mathrm{~K}$ array, the Genome-Wide Human SNP Array 5.0 and 6.0, the porcine $60 \mathrm{~K} \mathrm{SNP}$ array [27], the bovine $50 \mathrm{KSNP}$ array [28], the chicken $60 \mathrm{~K}$ [29] and $600 \mathrm{~K}$ SNP arrays [30], the canine $22 \mathrm{k} \mathrm{SNP}$ array [31], and the equine $50 \mathrm{~K}$ SNP array [32]. These arrays have been used widely for research on selective sweeps, phylogeny, population structure, copy number variations, GWAS, and other aspects [32-36], boosting genome and genetic studies as well as breeding programs of these species.

Although the importance of high-density SNP genotyping arrays has been recognized widely, as yet there are only a few such SNP genotyping arrays for aquaculture species. After the submission of this manuscript, an Affymetrix Axiom myDesign Custom Array containing 132,033 Atlantic salmon SNPs was developed [37]. Meanwhile, an Affymetrix Axiom Array containing 204,437 putative catfish SNPs was also developed [38]. Although a large research community is working on C. carpio and other closely related Cyprinid species, and genotyping is performed intensively for diverse purposes, no SNP genotyping array is available for C. carpio.

Here, we report the design and validation of the first high-density C. carpio SNP array, the Carp SNP array, based on the Affymetrix Axiom platform. The Carp SNP array was validated with 1,072 samples from various C. carpio populations and strains. To assess its potential use in closely related Cyprinids, we also validated the array in 80 individuals from eight related species. A pilot study was conducted to demonstrate the accuracy and efficiency of the genome-scale genotyping and linkage disequilibrium (LD) decay was analyzed in all samples and in several domesticated strains. Identity by state (IBS) clustering of all samples was conducted, which demonstrated the reliability of the Carp SNP array.

\section{Results and discussion}

The pipeline and design parameters described below are summarized in Figure 1.

\section{Sequencing and alignment of sequence reads}

In previous studies, over 700,000 SNPs have been identified in transcript sequences and classified [5]. All these SNPs were mapped to the reference genome and assigned to genomic positions. However, because these SNPs are from transcribed sequences, their numbers are limited and represent only the SNPs in coding sequences. To improve on this situation, we selected 18 representative carps for genome re-sequencing, including seven accessions of two wild populations from the 
SNP discovery stage

- SNP calling: base quality $\geq \mathbf{2 0}$, mapping quality $\geq \mathbf{2 0}$

- SNP filtering: SNP quality $\geq 20$, coverage $\geq 10$, $\operatorname{mac} \geq 2$, maf $\geq 5 \%$

- Choose shared SNPs by various strains and strain-specific SNPs

- Transcriptome SNPs: classify and blast to reference genome

\section{$\checkmark$}

SNP flanking sequence quality and close proximity

- No 'GGGG' or 'CCCC' or 'AAAAAA' or 'TTTTTT', no 'N'

- GC content between $30 \%$ and $70 \%$

- Uniquely mapped to genome

- No other SNP within 10bp, at most 1 SNP within 35bp

SNP in-silico analysis on probes

- Remove duplicated sequences and highly repetitive sequences

- Remove probes with $p$ convert value $<0.58$

Final 250k panel for array from above list of SNPs

- 150k cSNPs chosen in priority

- 100k genome SNPs chosen by certain intervals

Figure 1 Pipeline of carp SNP array development.

Yellow and Heilongjiang rivers, and 11 accessions of three domesticated strains (Songpu, Oujiang color, and Hebao). Re-sequencing of these 18 accessions generated a total of 2,281 million paired-end reads that were $101 \mathrm{bp}$ long $(228.1 \mathrm{~Gb})$. All raw sequencing data have been deposited in the NCBI Sequence Read Archive [SRA: SRP026407]. The short reads were mapped to the reference genome, with an average sequencing depth of six genome equivalent per animal. The mapping coverage rate was an average of $87.6 \%$ (Table 1 ).

\section{SNP identification}

SNP identification was performed separately within each strain. The criteria used for calling SNPs were as following: (1) mapping quality score $\geq 20$; (2) relevant base quality score $\geq 20$; (3) SNP quality score $\geq 20$ and SNP position must be covered by at least 10 reads; and (4) minor allele count $(\mathrm{MAC}) \geq 2$ and minor allele frequency $(\mathrm{MAF}) \geq 5 \%$. A total of 8,058,251 SNPs were identified in Songpu carp, 11,412,638 SNPs in Yellow River carp, 8,688,799 SNPs in Heilongjiang River carp, 7,123,672 SNPs in Oujiang color carp, and 9,955,915 SNPs in Hebao carp (Table 2). Overall, a total of 24,272,905 non-redundant SNPs were identified, of which 802,209 were shared by all strains, and $13,811,200$ were strain-specific. Together with the SNPs identified previously in the transcript sequences, we had a pool of 15,366,108 SNPs from which to select SNPs for the carp array. An abundant source of candidate SNPs is essential for designing SNP arrays, especially for large genomes like the $C$. carpio genome. When the dog SNP array was developed, more than 2.5 million potential SNPs were identified, with one SNP per $0.9 \mathrm{~kb}$ between breeds and one SNP per $1.5 \mathrm{~kb}$ within breeds. In other studies, 2.8 million SNPs were detected in chicken [9], and 1.1 million SNPs were discovered in horse [36]. Thus, based on these previous studies, it is evident that we had gathered a

Table 1 Genome re-sequencing data

\begin{tabular}{|c|c|c|c|c|c|}
\hline Accession & Raw bases (G) & Mapped bases (G) & Mapping rate (\%) & Coverage rate $(\%)$ & Depth \\
\hline Songpu carp 1 & 11.71 & 9.90 & 84.54 & 89.32 & 5.84 \\
\hline Songpu carp 2 & 12.39 & 10.40 & 83.93 & 89.09 & 6.14 \\
\hline Songpu carp 3 & 12.66 & 10.64 & 84.10 & 89.35 & 6.28 \\
\hline Songpu carp 4 & 11.45 & 9.62 & 84.02 & 88.58 & 5.68 \\
\hline Yellow River carp 1 & 10.40 & 8.30 & 79.87 & 86.62 & 4.90 \\
\hline Yellow River carp 2 & 10.43 & 8.33 & 79.84 & 87.04 & 4.91 \\
\hline Yellow River carp 3 & 11.92 & 9.08 & 76.16 & 87.19 & 5.36 \\
\hline Yellow River carp 4 & 14.01 & 11.11 & 79.31 & 89.18 & 6.56 \\
\hline Heilongjiang River carp 1 & 13.40 & 9.21 & 68.75 & 86.73 & 5.44 \\
\hline Heilongjiang River carp 2 & 16.13 & 12.25 & 75.93 & 89.72 & 7.23 \\
\hline Heilongjiang River carp 3 & 15.22 & 9.46 & 62.20 & 87.49 & 5.58 \\
\hline Hebao carp 1 & 9.86 & 7.92 & 80.32 & 85.60 & 4.67 \\
\hline Hebao carp 2 & 13.63 & 9.53 & 69.90 & 85.63 & 5.62 \\
\hline Hebao carp 3 & 13.07 & 10.36 & 79.23 & 88.28 & 6.11 \\
\hline Hebao carp 4 & 12.54 & 10.21 & 81.44 & 88.11 & 6.03 \\
\hline Oujiang color carp 1 & 11.98 & 9.65 & 80.52 & 87.00 & 5.69 \\
\hline Oujiang color carp 2 & 11.39 & 8.23 & 72.27 & 85.65 & 4.86 \\
\hline Oujiang color carp 3 & 10.66 & 8.26 & 77.48 & 85.63 & 4.87 \\
\hline
\end{tabular}


Table 2 SNP identification from genome re-sequencing

\begin{tabular}{lccc}
\hline Strain & No. SNPs & No. strain-specific & No. shared \\
\hline Songpu mirror carp & $8,058,251$ & $2,434,141$ & \\
Yellow River carp & $11,412,638$ & $3,674,888$ & \\
Heilongjiang River carp & $8,688,799$ & $2,337,049$ & 802,209 \\
Oujiang color carp & $7,123,672$ & $2,209,060$ & \\
Hebao carp & $9,955,915$ & $3,156,062$ & \\
Non-redundant & & $24,272,905$ & \\
\hline
\end{tabular}

sufficient number of candidate SNPs to develop a C. carpio SNP array.

\section{SNP reduction based on flanking sequence quality and close proximity}

For quality control, 71-bp fragments spanning each SNP were extracted, including 35-bp upstream and 35-bp downstream of the SNP base. SNPs with flanking sequences that containing over four consecutive ' $G$ ' or ' $C$ ' or over six consecutive 'A' or ' $\mathrm{T}$ ', and those containing ' $N$ ' were removed, resulting in 13,431,573 SNPs. Next, GC content was calculated and SNPs with flanking sequences with GC content below $30 \%$ or above $70 \%$ were removed. The flanking sequences of the remaining $11,307,040$ SNPs were mapped to the reference genome, and the 8,450,637 SNPs that mapped uniquely were kept for further selection. SNPs located very close to each other are less likely to be assayed successfully during genotyping because of interference from neighboring variants. Clustering of SNPs can be a result of the misalignment of reads because of the presence of the indels (insertions or deletions) at the beginning or end of reads [39]. Based on advice from Affymetrix scientists, we removed SNPs that were within $10 \mathrm{bp}$ of each other or there were more than two variants within $35 \mathrm{bp}$. After these steps, 3,719,260 SNPs remained in the final pool for selection. Priority was given to SNPs in coding sequences, and then the genome re-sequencing SNPs were selected on the basis of their quality scores and spacing on the genome. Finally, a total of 378,815 SNPs were submitted for probe design.

\section{SNP reduction based on in-silico analysis of conversion values}

The 378,815 selected SNPs were submitted to Affymetrix for in-silico analysis to predict their reproducibility on the Axiom platform. The p -convert value, which is calculated using a random forest model, is designed to predict the probability that the SNP will convert on the array. The random forest model considers many factors, such as probe sequence, binding energies, unexpected non-specific binding and probability of hybridization to multiple genomic regions [30]. P-convert values were generated for the forward and reverse probes and $\mathrm{p}$ - convert values $\geq 0.58$ were considered to be qualified. As shown in Figure 2, a high proportion of the 378,815 SNPs $(347,712 ; 91.8 \%)$ had a p-convert value $\geq 0.58$.

\section{SNP selection for the final Carp array}

In this final step, we selected 250,000 SNPs in the following order: (1) 8,204 non-synonymous SNPs and 5,219 SNPs in UTR regions with each SNP at least 100 bp from any adjacent SNP; (2) 133,603 SNPs in transcribed sequences that were at least $1.8 \mathrm{~kb}$ from any adjacent selected SNP; (3) 100,974 SNPs from the genome re-sequencing data that were shared between strains and separated by at least $10 \mathrm{~kb}$ from any adjacent selected SNP; and (4) 2,000 strain-specific SNPs that were at least $17 \mathrm{~kb}$ from any other SNP on the array (Table 3). As shown in Figure 3, the average interval between the final 250,000 SNPs was $6.6 \mathrm{~kb}$, and the intervals between most SNPs ranged from 3 to $8 \mathrm{~kb}$. When the SNP densities on the assembled C. carpio chromosomes were calculated, we found that the SNP densities ranged from 137 sites/Mb to 187 sites/Mb. Scaffolds that have not been assigned to one of the 50 chromosomes were joined to form a pseudo 'P' chromosome, which had a SNP density of 122 sites/Mb (Figure 4). Thus, the average number of SNPs per unit physical distance indicates that the SNPs are uniformly distributed across the genome.

\section{Evaluation of the SNP array in C. carpio strains}

After the Carp array was manufactured, we evaluated the array in both $C$. carpio and related carp species. A total of 1,072 C. carpio samples were collected from various strains, including Songpu carp, Hebao carp, Yellow River carp, Oujiang color carp, Xingguo red carp, and Heilongjiang carp. Of the 250,000 candidate SNPs, 223,274 (89.3\%) passed the manufacturing quality control and could be genotyped. With a stringent call rate threshold of 95\%, there were $185,150 \quad(74.06 \%)$

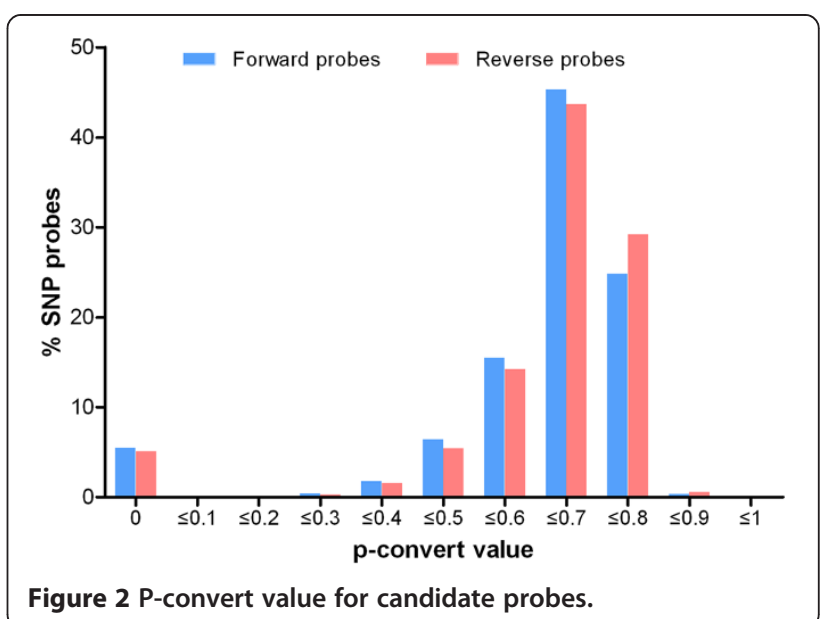


Table 3 Number of SNPs during SNP array designation

\begin{tabular}{|c|c|c|c|c|c|c|c|c|}
\hline \multirow[t]{2}{*}{ Category } & \multirow[t]{2}{*}{ Original } & \multicolumn{5}{|c|}{ Stage 1} & \multicolumn{2}{|c|}{ Stage 2} \\
\hline & & $\begin{array}{c}\text { Repetitive } \\
\text { nucleotides }\end{array}$ & $\begin{array}{c}\text { GC } \\
\text { content }\end{array}$ & $\begin{array}{l}\text { Unique } \\
\text { mapping }\end{array}$ & $\begin{array}{l}\text { Adjacent } \\
\text { SNPs }\end{array}$ & $\begin{array}{c}\text { Pre- } \\
\text { screen }\end{array}$ & $\begin{array}{l}\text { Probe } \\
\text { QC }\end{array}$ & Final \\
\hline $\begin{array}{l}\text { Transcriptome } \\
\text { sequencing }\end{array}$ & & & & & & & & 147,026 \\
\hline Non-synonymous & 47,137 & 32,489 & 32,315 & 25,211 & 11,813 & 9,669 & 8,204 & 8,204 \\
\hline $3^{\prime} \cup T R$ & 19,639 & 13,734 & 12,758 & 11,314 & 5,340 & 3,819 & 3,616 & 3,616 \\
\hline $5^{\prime}$ UTR & 8,145 & 6,488 & 6,420 & 5,042 & 2,516 & 1,864 & 1,603 & 1,603 \\
\hline Others & 670,325 & 629,039 & 586,832 & 475,850 & 220,137 & 155,437 & 140,879 & 133,603 \\
\hline \multicolumn{2}{|c|}{ Genome re-sequencing } & & & & & & & 102,974 \\
\hline Strain-shared & 809,662 & 745,423 & 660,045 & 532,121 & 213,189 & 168,216 & 157,579 & 100,974 \\
\hline Strain-specific & $13,811,200$ & $12,004,400$ & $10,008,670$ & $7,401,099$ & $3,266,265$ & 39,810 & 35,831 & 2,000 \\
\hline Total & $15,366,108$ & $13,431,573$ & $11,307,040$ & $8,450,637$ & $3,719,260$ & 378,815 & 347,712 & 250,000 \\
\hline
\end{tabular}

polymorphic sites, 4,202 (1.68\%) sites with no minor homology genotype, 180 (0.07\%) monomorphic sites, and $33,742(13.50 \%)$ sites below the call rate threshold (Table 4). Although 185,150 (74.06\%) polymorphic SNPs had been validated in this study, it does not mean that only 185,150 loci are polymorphic. More SNP loci will be validated when more strains harboring a new genetic background are genotyped using this array. Genotyping accuracies were estimated using samples from families and the results seemed to be satisfactory (data not shown). Of the189,532 SNPs that passed the call rate threshold, $80.0 \%$ had a MAF $>0.10$ and $63.3 \%$ had a MAF $>0.20$, indicating that most of the SNPs will be applicable in subsequent research.

\section{Accuracy of genotyping for the SNP array}

High accuracy is a vital parameter for a genotyping platform. In this study, we assessed the genotyping accuracy of our Carp array using data from a family comprising

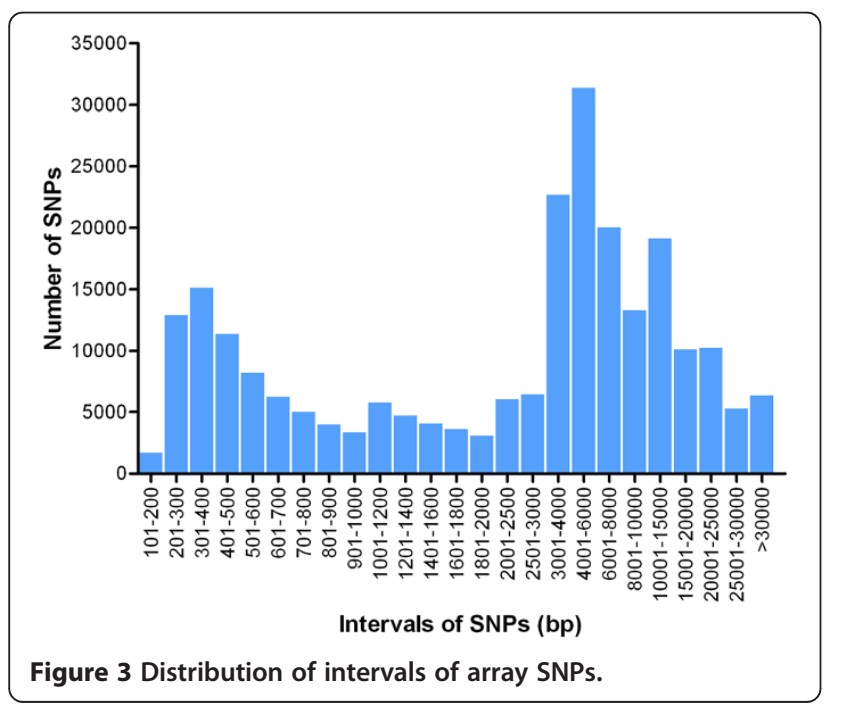

two parents and 80 offspring. PLINK software was applied with the 'Mendel' parameter. Any genotypes not concordant between parents and offspring were regarded as genotyping errors. We estimated the accuracy to be 99.6\% on average, and after excluding one sample because of multiple inconsistencies with the inheritance pattern expected on the basis of the declared pedigree, the genotyping accuracy increased to $99.8 \%$ on average, showing the high genotyping quality of the Carp array. Thus, in subsequent research, this array will be of great importance in trait association analysis, QTL mapping, and marker assisted selection.

\section{Extensive assessment of the SNP array in Cyprinids}

We evaluated the SNP array in 80 samples from the $C$. carpio related species, such as Carassius carassius, Ctenopharyngodon idella, Mylopharyngodon piceus, Hypophthalmichthys molitrix, Hypophthalmichthys nobilis, Megalobrama amblycephala, Danio rerio, Leuciscus waleckii, and 84,933 (34.0\%) SNPs were found to be polymorphic. With a moderate call rate threshold of $80 \%$, there were 54,116 (21.65\%) polymorphic sites, $6,748(2.70 \%)$ sites with no minor homology genotype, $88(0.04 \%)$ monomorphic sites, and 23,981 (9.59\%) sites below the call rate threshold (Table 4). A detailed analysis of the eight Cypridinae species is shown in Table 5. The number of SNPs that exhibited variations for each species ranged from 53,526 to 71,984, demonstrating that the SNP array is potentially useful for studies of carp-related species. After filtering the SNP call rate, the remaining number of SNPs range from 29,870 to 59,020 among the eight species. The significant difference in the SNP numbers before and after filtering is mainly because of the small sample sizes. From the eight Cypridinae species, we collected 15 samples of $D$. rerio, five samples of L. waleckii, and 10 samples for other six species. In future research, as large numbers of samples are 


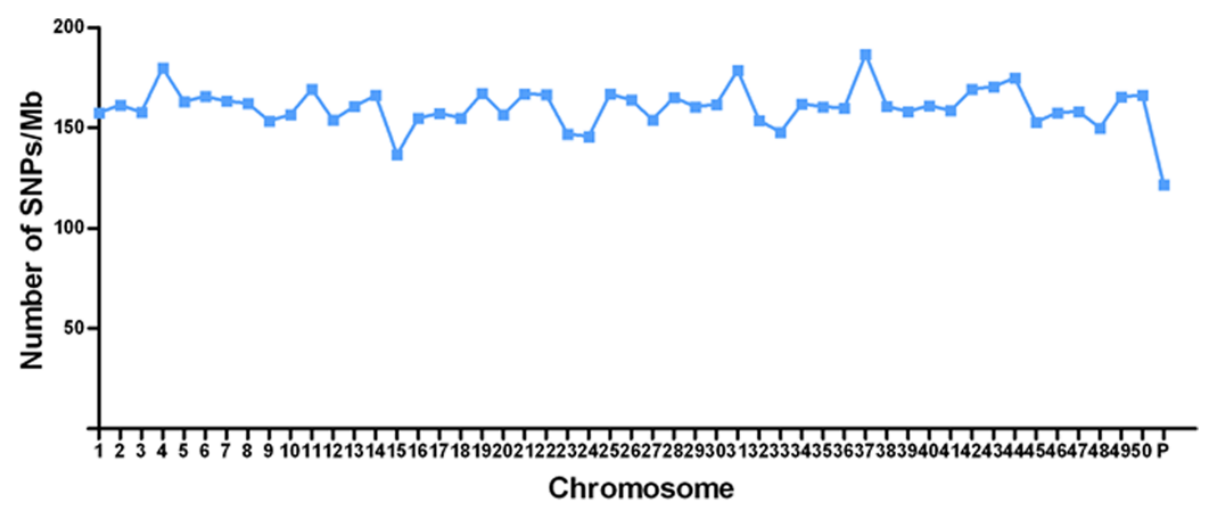

Figure 4 Densities of SNPs over 50 chromosomes and unassembled scaffolds. Densities of SNPs were calculated on 50 chromosomes by a unit of 1 million base pair. SNPs on unassembled scaffolds were joined together to form a pseudo "P" chromosome.

collected, more of the SNPs on the array may pass the call-rate threshold. Among these eight species, D. rerio is the only species for which a genome assembly has been reported.

\section{Linkage disequilibrium (LD) analysis}

The extent of LD across the SNPs that are on the array was analyzed for all the samples of $C$. carpio and for three of the domesticated strains, Yellow River carp, Hebao carp, and Xingguo red carp. Pairwise $r^{2}$ was calculated using 82,113 SNP markers with MAFs over 0.05 for 120,395 samples for Yellow River carp, 73,703 for Hebao carp, and 86,517 for Xingguo red carp. The average $r^{2}$ within each kilo base pair was calculated and plotted against the physical distance (Figure 5). A similar trend of LD decay was observed in all samples and in each strain, showing that the LD blocks in C. carpio are shorter than most other species [40-45]. On the other hand, the LD blocks in these three strains are relatively longer than the LD blocks in all the samples tested, probably because of simpler genetic background within each strain. Similar results have been reported in other species; for example, the domestic dog in which much longer LD blocks have been reported in each breed compared with in mixed samples [44]. In a future study, we will use larger samples of each strain for LD analysis and construct haplotypes, which will be useful for the design of medium or low density SNP panels. As observed previously in several domesticated animals $[46,47]$, lower density SNP panels can be designed and applied for genomic selection and breeding, with fewer tag markers selected on interesting traits.

\section{Population structure analysis through identity by state (IBS) clustering}

Population structure analyses have commonly been conducted before GWAS analyses [48,49] and several methods for population stratification have been developed, such as IBS and principle component analysis (PCA). In this study, genotyping was performed on 1,072 samples of C. carpio and on 80 samples of another eight related species. After quality control 73,377 markers and 1,152 samples passed all the criteria. Multidimensional scaling analysis of an IBS matrix revealed the substructure of the samples (Figure 6). All the samples were divided into three clusters. All the C. carpio samples (except Oujiang color carp and Heilongjiang carp) formed the largest cluster, within which different

Table 4 Evaluation of SNP array in all samples

\begin{tabular}{|c|c|c|c|c|c|c|}
\hline \multirow[t]{2}{*}{ Category } & \multicolumn{3}{|c|}{ C. carpio } & \multicolumn{3}{|c|}{ Related species of $C$. carpio } \\
\hline & Percentage (\%) & SNP count & Probe count & Percentage (\%) & SNP count & Probe count \\
\hline Poly high resolution & 74.06 & 185,150 & 220,615 & 21.65 & 54,116 & 60,143 \\
\hline No minor homology & 1.68 & 4,202 & 7,173 & 2.70 & 6,748 & 8,772 \\
\hline Mono high resolution & 0.07 & 180 & 315 & 0.04 & 88 & 126 \\
\hline Call rate below threshold & 13.50 & 33,742 & 58,146 & 9.59 & 23,981 & 32,564 \\
\hline Off Target Variation (OTV) & 1.15 & 3,610 & 3,610 & 4.38 & 10,941 & 20,424 \\
\hline Other & 9.54 & 23,844 & 26,734 & 61.65 & 154,126 & 194,564 \\
\hline Total & 100.00 & 250,000 & 316,593 & 100 & 250,000 & 316,593 \\
\hline
\end{tabular}


Table 5 Evaluation of SNP array in eight Cyprinus carpio related species

\begin{tabular}{|c|c|c|c|c|c|c|c|c|}
\hline \multirow[t]{2}{*}{ Category } & \multicolumn{8}{|c|}{ SNP count } \\
\hline & $\begin{array}{l}\text { C. carassius } \\
(n=10)\end{array}$ & $\begin{array}{c}\text { M. piceus } \\
(\mathrm{n}=10)\end{array}$ & $\begin{array}{l}\text { C. idella } \\
(\mathrm{n}=10)\end{array}$ & $\begin{array}{c}\text { H. molitrix } \\
(\mathrm{n}=10)\end{array}$ & $\begin{array}{c}\text { H. nobilis } \\
(\mathrm{n}=10)\end{array}$ & $\begin{array}{c}\text { M. amblycephala } \\
(\mathrm{n}=10)\end{array}$ & $\begin{array}{l}\text { D. rerio } \\
(n=15)\end{array}$ & $\begin{array}{l}\text { L. waleckii } \\
(\mathrm{n}=5)\end{array}$ \\
\hline Poly high resolution & 17,447 & 30,872 & 8,162 & 9,153 & 18,629 & 18,816 & 2,911 & 1,556 \\
\hline No minor homology & 30,581 & 28,148 & 27,880 & 27,514 & 28,623 & 31,707 & 37,499 & 28,314 \\
\hline Mono high resolution & 0 & 0 & 0 & 0 & 0 & 0 & 0 & 0 \\
\hline Call rate below threshold & 22,240 & 12,964 & 19,192 & 19,230 & 18,532 & 16,751 & 14,533 & 23,656 \\
\hline Off Target Variation (OTV) & 10,941 & 10,941 & 10,941 & 10,941 & 10,941 & 10,941 & 10,941 & 10,941 \\
\hline Other & 168,791 & 167,075 & 183,825 & 183,162 & 173,275 & 171,785 & 184,116 & 185,533 \\
\hline Total & \multicolumn{8}{|c|}{250,000} \\
\hline
\end{tabular}

strains were grouped together. The Oujiang color carp and Heilongjiang carp genotyping results were both from the first 96-well plate of this array, so a replicate experiment should be performed along with the next batch of samples. C. carassius, D. rerio and L. waleckii formed the second cluster, close to the largest cluster. The third cluster consisted of $C$. idella, M. piceus, $H$. molitrix, $H$. nobilis and $M$. amblycephala and showed distinct divergences from the other two clusters. The IBS clustering results are consistent with several phylogenetic analyses of Cyprinidae reported previously [50-52], indicating that the Carp SNP array is reliable and potentially has applications in breeding.

\section{Conclusions}

We developed the Carp SNP array which is the first high-throughput genotyping platform for C. carpio. After evaluation with large samples, nearly three fourths

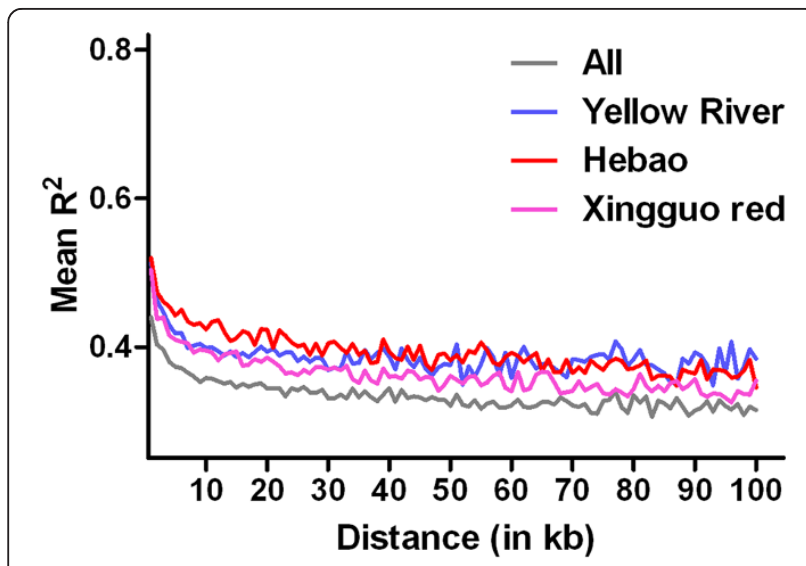

Figure 5 Decay of linkage disequilibrium (LD) among all samples and three domesticated strains. LD decay within a range of $100 \mathrm{~kb}$ was plotted on all samples and three domesticated strains. Average $r^{2}$ value of each $1 \mathrm{~kb}$ region was calculated $(Y$ axis), and physical distances of SNPs was assigned to $X$ axis in unit of $\mathrm{kb}$. $\mathrm{X}-\mathrm{Y}$ plots were drawn among all samples (grey), within Hebao carp (red), within Yellow River carp (blue), and within Xingguo red carp (purple). of the designed 250,000 SNPs proved to be polymorphic in $C$. carpio. Besides, the Carp SNP array was also evaluated in related species. LD was calculated and longer haplotype blocks were observed in domesticated strains. IBS was conducted and most of the samples were assigned to different clusters. This study indicates that the Carp SNP array will be valuable for farmed carp and for genetic and population biology studies in C. carpio and related species.

\section{Methods}

\section{Ethics statement}

This study was approved by the Animal Care and Use Committee (ACUC) of the Centre for Applied Aquatic

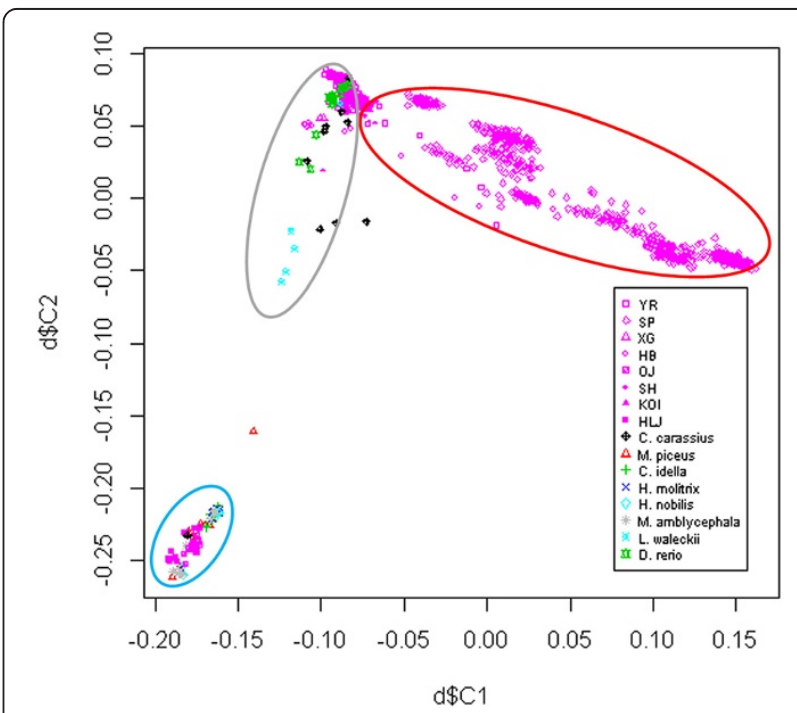

Figure 6 IBS clustering of all samples. MDS file was extracted and plotted using $\mathrm{R}$ package. The first dimension ( $\mathrm{d} \$ \mathrm{C} 1$ ) was assigned to $X$ axis, and the second dimension (d\$C2) was assigned to $Y$ axis. Purple symbols represented C. carpio samples, and different strains were plotted with different shapes. YR represents Yellow River carp, SP for Songpu mirror carp, XG for Xingguo red carp, HB for Hebao carp, SH for Songhe carp, and KOI for Koi. Symbols with other colors represented other eight species. 
Genomics at the Chinese Academy of Fishery Sciences. All sampling procedures complied with the guidelines of ACUC on the care and use of animals for scientific purposes.

\section{Sample collection and genome re-sequencing}

Five strains (here a "strain" is defined as a domestic population with unique characteristics; different strains belong to the same species) of C. carpio comprising 18 accessions (here "accession" means individual) were collected. The five strains were Songpu carp from Heilongjiang Fishery Research Institute, Yellow River carp from Henan Academy of Fishery Sciences, Heilongjiang River carp from Fuyuan County in Heilongjiang Province, Hebao carp from Wuyuan County in Jiangxi Province, and Oujiang color carp from Longquan County in Zhejiang Province. Fin chips or blood samples were collected and DNA was extracted using a DNeasy Blood \& Tissue Kit (Qiagen, Shanghai, China). The samples are listed in Table 1. DNA library preparation and sequencing were carried out at the HudsonAlpha Genomic Services Laboratory (Huntsville, AL, USA) following the manufacturer's instructions. After KAPA quantitation and dilution, the library was sequenced on Illumina HiSeq 2000 to generate 101 bp paired-end reads.

\section{SNP identification}

The paired-end reads from each accession were aligned to the reference genome using BWA [53] to generate sequence alignment/map SAM files. After mapping, SNPs were identified on the basis of the mpileup files generated by SAMtools [54]. The variant call format (VCF) files were manipulated further using custom-made scripts for primary filtration based on depth and quality.

\section{SNP selection}

SNP selection was carried out in multiple steps using different criteria. All the filtration parameters were set to minimize the risk of false positive sites and to select SNPs that were relatively evenly distributed across the genome. All the original SNPs were classified to six different databases and selected in a certain order. First, non-synonymous SNPs and SNPs in UTR regions were selected; then other transcriptome SNPs were added; and finally, strain-shared and strain-specific SNPs were added to the pool of candidate SNPs. During the SNP selection steps, several custom-made scripts were used to qualify flanking sequences. To ensure an even distribution of SNPs over the genome, a custom-made algorithm (described below) was used. When a new SNP was introduced into the final pool, a threshold of $t$ bases was set and SNPs within the $t$ bases were excluded. For SNPs that originated from the transcriptome data, $t$ was set lower than $2 \mathrm{~kb}$ so that all the cSNPs were included in the final pool. For SNPs from the genome re-sequencing data, $t$ was set over $10 \mathrm{~kb}$ because most of these SNPs were from non-coding regions.

\section{Evaluation of the SNP array}

To evaluate the Carp SNP array, 1,072 samples from $C$. carpio and 80 samples from carp-related species were collected. Genomic DNA was extracted from blood using a DNeasy 96 Blood \& Tissue Kit (Qiagen). All the DNA samples were quantified by NanodropND-1000 spectrophotometer (NanoDrop Technologies Inc., Wilmington, DE, USA) and sent to GeneSeek (Lansing, MI) for genotyping. The genotype data were extracted and converted to Ped/Map format. PLINK software [55] was used to classify the SNPs and extract the data for the different species. Mendelian analysis and LD decay were also conducted with PLINK using the "-mendel" and “-r2" parameters. Mendelian analysis was conducted on family data for two parents and 80 offspring, following the procedure reported previously [56]. X-Y plots were drawn using the average $r^{2}$ values ( $Y$ axis) and the physical distances (X axis) for each pair of SNPs each kilo base-pair. IBS clustering was conducted with PLINK using the "-mds-plot 2", "-cluster", and "-genome" parameters, with a P-value threshold of 1E-3. The PLINK MDS file was extracted and a scatter plot was drawn using $\mathrm{d} \$ \mathrm{C} 1$ ( $\mathrm{X}$ axis) and $\mathrm{d} \$ \mathrm{C} 2$ (Y axis) in the $\mathrm{R}$ software package (version 3.0.2, Vienna, Austria).

\section{Competing interests}

The authors declare that they have no competing interests.

\section{Authors' contributions}

JX worked on sample collection, genome sequencing, SNP identification and evaluation, array design and manuscript preparation. ZZ worked on sample collection and SNP array evaluation. XZ, XZheng, YK, JL, YZ, JF, CL, JY, QL established C. carpio families of multiple strains, and collected samples for array analysis. YJ participated in manuscript preparation. QL, YZhu and YLiu worked on DNA extraction. PX conceived and supervised C. carpio SNP identification and the array project. XS supervised the C. carpio genome project. All authors read and approved the final manuscript.

\section{Acknowledgements}

We acknowledge grant support from the National High-Technology Research and Development Program of China (863 program; 2011AA100401 and 2011AA100402), National Department Public Benefit Research Foundation of China (200903045), and China Ministry of Agriculture "948" Program (No. 2013- Z12). PX would like to thank the Visiting Professorship Program, Deanship of Scientific Research, College of Sciences at King Saud University, Riyadh.

\section{Author details}

${ }^{1}$ Centre for Applied Aquatic Genomics, Chinese Academy of Fishery Sciences, Beijing 100141, China. ${ }^{2}$ Heilongjiang Fisheries Research Institute, Chinese Academy of Fishery Sciences, Harbin 150070, China. ${ }^{3}$ Henan Academy of Fishery Sciences, Zhengzhou, Henan 450044, China. ${ }^{4}$ Yangtze River Fisheries Research Institute, Chinese Academy of Fishery Sciences, Wuhan 430223, China. ${ }^{5}$ Freshwater Fisheries Research Center, Chinese Academy of Fishery Sciences, Wuxi 430223, China. ${ }^{6}$ Visiting Professor Department of Zoology, College of Science, King Saud University, P. O. Box 24555, Riyadh 11451, Saudi Arabia. 
Received: 9 September 2013 Accepted: 17 April 2014

Published: 24 April 2014

\section{References}

1. Fisheries F: Aquaculture Department: The State of World Fisheries and Aquaculture 2006. Rome: Food and Agriculture Organization of the United Nations; 2007.

2. Bostock J, McAndrew B, Richards R, Jauncey $K$, Telfer T, Lorenzen $K$, Little $D$, Ross L, Handisyde N, Gatward I, Corner R: Aquaculture: global status and trends. Philos T R Soc B 2010, 365(1554):2897-2912

3. Ji P, Zhang Y, Li C, Zhao Z, Wang J, Li J, Xu P, Sun X: High throughput mining and characterization of microsatellites from common carp genome. Int J Mol Sci 2012, 13(8):9798-9807.

4. Zheng X, Kuang Y, Lv W, Cao D, Zhang X, Li C, Lu C, Sun X: A consensus linkage map of common carp (Cyprinus carpio L.) to compare the distribution and variation of QTLs associated with growth traits. Sci China Life Sci 2013, 56(4):351-359.

5. Xu J, Ji P, Zhao Z, Zhang Y, Feng J, Wang J, Li J, Zhang X, Zhao L, Liu G, Xu $P$, Sun $X$ : Genome-wide SNP discovery from transcriptome of four common carp strains. PLoS One 2012, 7(10):e48140.

6. Kongchum P, Palti Y, Hallerman EM, Hulata G, David L: SNP discovery and development of genetic markers for mapping innate immune response genes in common carp (Cyprinus carpio). Fish Shellfish Immunol 2010, 29(2):356-361.

7. Zhang X, Zhang Y, Zheng X, Kuang Y, Zhao Z, Zhao L, Li C, Jiang L, Cao D, Lu C, XU P, Sun $X$ : A consensus linkage map provides insights on genome character and evolution in common carp (Cyprinus carpio L.). Mar Biotechnol 2013, 15(3):275-312.

8. Zhao L, Zhang Y, Ji P, Zhang X, Zhao Z, Hou G, Huo L, Liu G, Li C, Xu P, Sun $X$ : A dense genetic linkage map for common carp and its integration with a BAC-based physical map. PLoS One 2013, 8(5):e63928.

9. Wong GK, Liu B, Wang J, Zhang Y, Yang X, Zhang Z, Meng Q, Zhou J, Li D, Zhang J, Ni P, Li S, Ran L, Li H, Li R, Zheng H, Lin W, Li G, Wang X, Zhao W, Li J, Ye C, Dai M, Ruan J, Zhou Y, Li Y, He X, Huang X, Tong W, Chen J, et al: A genetic variation map for chicken with 2.8 million single-nucleotide polymorphisms. Nature 2004, 432(7018):717-722.

10. Cheng L, Liu L, Yu X, Wang D, Tong J: A linkage map of common carp (Cyprinus carpio) based on AFLP and microsatellite markers. Anim Genet 2010, 41(2):191-198.

11. Liu J, Zhang L, Xu L, Ren H, Lu J, Zhang X, Zhang S, Zhou X, Wei C, Zhao F, Du L: Analysis of copy number variations in the sheep genome using 50 K SNP BeadChip array. BMC Genomics 2013, 14:229.

12. Zhang Y, Xu P, Lu C, Kuang Y, Zhang X, Cao D, Li C, Chang Y, Hou N, Li H: Genetic linkage mapping and analysis of muscle fiber-related QTLs in common carp (Cyprinus carpio L.). Mar Biotechnol 2011, 13(3):376-392.

13. Xu J, Huang W, Zhong C, Luo D, Li S, Zhu Z, Hu W: Defining global gene expression changes of the hypothalamic-pituitary-gonadal axis in female sGnRH-antisense transgenic common carp (Cyprinus carpio). PLoS One 2011, 6(6):e21057.

14. Williams DR, Li W, Hughes MA, Gonzalez SF, Vernon C, Vidal MC, Jeney Z, Jeney G, Dixon P, McAndrew B, Bartfai R, Orban L, Trudeau V, Rogers J, Matthews L, Fraser EJ, Gracey AY, Cossins AR: Genomic resources and microarrays for the common carp Cyprinus carpio L. J Fish Biol 2008, 72(9):2095-2117.

15. Christoffels A, Bartfai R, Srinivasan H, Komen H, Orban L: Comparative genomics in cyprinids: common carp ESTs help the annotation of the zebrafish genome. BMC Bioinforma 2006, 7(Suppl 5):S2.

16. Ji $P$, Liu G, Xu J, Wang $X$, Li J, Zhao Z, Zhang $X$, Zhang $Y$, Xu P, Sun X: Characterization of common carp transcriptome: sequencing, de novo assembly, annotation and comparative genomics. PLoS One 2012, 7(4):e35152

17. Moens LN, van der Ven K, Van Remortel P, Del-Favero J, De Coen W: Gene expression analysis of estrogenic compounds in the liver of common carp (Cyprinus carpio) using a custom cDNA microarray. J Biochem Mol Toxicol 2007, 21(5):299-311.

18. Li Y, Xu P, Zhao Z, Wang J, Zhang Y, Sun XW: Construction and characterization of the BAC library for common carp Cyprinus carpio $\mathrm{L}$. and establishment of microsynteny with zebrafish Danio rerio. Mar Biotechnol 2011, 13(4):706-712.

19. Xu P, Li J, Li Y, Cui R, Wang J, Zhang Y, Zhao Z, Sun X: Genomic insight into the common carp (Cyprinus carpio) genome by sequencing analysis of BAC-end sequences. BMC Genomics 2011, 12:188.
20. Xu P, Wang J, Wang J, Cui R, Li Y, Zhao Z, Ji P, Zhang Y, Li J, Sun X: Generation of the first BAC-based physical map of the common carp genome. BMC Genomics 2011, 12(1):537.

21. Mabuchi K, Miya M, Senou H, Suzuki T, Nishida M: Complete mitochondrial DNA sequence of the Lake Biwa wild strain of common carp $(<i>$ Cyprinus carpio $</ \mathrm{i}>\mathrm{L}$.): further evidence for an ancient origin. Aquaculture 2006, 257(1):68-77.

22. Mabuchi $\mathrm{K}$, Song $\mathrm{H}$ : The complete mitochondrial genome of the Japanese ornamental koi carp (Cyprinus carpio) and its implication for the history of koi. Mitochondrial DNA 2013, 0:1-2.

23. Wang B, Ji P, Wang J, Sun J, Wang C, Xu P, Sun X: The complete mitochondrial genome of the Oujiang color carp, Cyprinus carpio var. color (Cypriniformes, Cyprinidae). Mitochondrial DNA 2013, 24(1):19-21.

24. Henkel CV, Dirks RP, Jansen HJ, Forlenza M, Wiegertjes GF, Howe K, van den Thillart GE, Spaink HP: Comparison of the exomes of common carp (Cyprinus carpio) and zebrafish (Danio rerio). Zebrafish 2012, 9(2):59-67.

25. Sun X, Yu J, Xu P, Wang X, Liu G, Li J, Zhang X, Kuang Y: Towards the Complete Genome: Progress of Common Carp Genome Project. San Diego: Plant and Animal Genome XX; 2012.

26. Baird NA, Etter PD, Atwood TS, Currey MC, Shiver AL, Lewis ZA, Selker EU, Cresko WA, Johnson EA: Rapid SNP discovery and genetic mapping using sequenced RAD markers. PLoS One 2008, 3(10):e3376.

27. Ramos AM, Crooijmans RP, Affara NA, Amaral AJ, Archibald AL, Beever JE, Bendixen C, Churcher C, Clark R, Dehais P, Hansen MS, Hedegaard J, Hu ZL, Kerstens HH, Law AS, Megens HJ, Milan D, Nonneman DJ, Rohrer GA, Rothschild MF, Smith TP, Schnabel RD, Van Tassell CP, Taylor JF, Wiedmann RT, Schook LB, Groenen MA: Design of a high density SNP genotyping assay in the pig using SNPs identified and characterized by next generation sequencing technology. PLoS One 2009, 4(8):e6524.

28. Matukumalli LK, Lawley CT, Schnabel RD, Taylor JF, Allan MF, Heaton MP, O'Connell J, Moore SS, Smith TP, Sonstegard TS, Van Tassell CP: Development and characterization of a high density SNP genotyping assay for cattle. PLoS One 2009, 4(4):e5350.

29. Groenen M, Megens H-J, Zare Y, Warren W, Hillier L, Crooijmans R, Vereijken A, Okimoto R, Muir W, Cheng H: The development and characterization of a 60 K SNP chip for chicken. BMC Genomics 2011, 12(1):274.

30. Kranis A, Gheyas AA, Boschiero C, Turner F, Yu L, Smith S, Talbot R, Pirani A, Brew F, Kaiser P, Hocking PM, Fife M, Salmon N, Fulton J, Strom TM, Haberer G, Weigend S, Preisinger R, Gholami M, Qanbari S, Simianer H, Watson KA, Woolliams JA, Burt DW: Development of a high density $600 \mathrm{~K}$ SNP genotyping array for chicken. BMC Genomics 2013, 14:59.

31. Meurs KM, Mauceli E, Lahmers S, Acland GM, White SN, Lindblad-Toh K: Genome-wide association identifies a deletion in the 3 ' untranslated region of striatin in a canine model of arrhythmogenic right ventricular cardiomyopathy. Hum Genet 2010, 128(3):315-324.

32. McCue ME, Bannasch DL, Petersen JL, Gurr J, Bailey E, Binns MM, Distl O, Guerin G, Hasegawa T, Hill EW, Leeb T, Lindgren G, Penedo MC, Roed KH, Ryder OA, Swinburne JE, Tozaki T, Valberg SJ, Vaudin M, Lindblad-Toh K, Wade CM, Mickelson JR: A high density SNP array for the domestic horse and extant Perissodactyla: utility for association mapping, genetic diversity, and phylogeny studies. PLoS Genet 2012, 8(1):e1002451

33. Utsunomiya YT, Perez O'Brien AM, Sonstegard TS, Van Tassell CP, Do Carmo AS, Meszaros G, Solkner J, Garcia JF: Detecting loci under recent positive selection in dairy and beef cattle by combining different genome-wide scan methods. PLoS One 2013, 8(5):e64280.

34. Boitard S, Rocha D: Detection of signatures of selective sweeps in the Blonde d'Aquitaine cattle breed. Anim Genet 2013, 44(5):579-583.

35. Bourret V, Kent MP, Primmer CR, Vasemägi A, Karlsson S, Hindar K, McGinnity P, Verspoor E, Bernatchez L, Lien S: SNP-array reveals genome-wide patterns of geographical and potential adaptive divergence across the natural range of Atlantic salmon (Salmo salar). Mol Ecol 2013, 22(3):532-551.

36. Wade CM, Giulotto E, Sigurdsson S, Zoli M, Gnerre S, Imsland F, Lear TL, Adelson DL, Bailey E, Bellone RR, Blocker H, Distl O, Edgar RC, Garber M, Leeb T, Mauceli E, MacLeod JN, Penedo MC, Raison JM, Sharpe T, Vogel J, Andersson L, Antczak DF, Biagi T, Binns MM, Chowdhary BP, Coleman SJ, Della Valle G, Fryc S, Guerin G: Genome sequence, comparative analysis, and population genetics of the domestic horse. Science 2009, 326(5954):865-867.

37. Houston RD, Taggart JB, Cezard T, Bekaert M, Lowe NR, Downing A, Talbot R, Bishop SC, Archibald AL, Bron JE, Penman DJ, Davassi A, Brew F, Tinch AE, Gharbi 
K, Hamilton A: Development and validation of a high density SNP genotyping array for Atlantic salmon (Salmo salar). BMC Genomics 2014, 15:90.

38. Liu S, Sun L, Li Y, Sun F, Jiang Y, Zhang Y, Zhang J, Feng J, Kaltenboeck L, Kucuktas H: Development of the catfish $250 \mathrm{~K} \mathrm{SNP}$ array for genomewide association studies. BMC Res Notes 2014, 7:135.

39. Abecasis GR, Altshuler D, Auton A, Brooks LD, Durbin RM, Gibbs RA, Hurles ME, McVean GA: A map of human genome variation from populationscale sequencing. Nature 2010, 467(7319):1061-1073.

40. Pemberton TJ, Absher D, Feldman MW, Myers RM, Rosenberg NA, Li JZ: Genomic patterns of homozygosity in worldwide human populations. Am J Hum Genet 2012, 91(2):275-292.

41. Tarazona-Santos E, Tishkoff SA: Divergent patterns of linkage disequilibrium and haplotype structure across global populations at the interleukin-13 (IL13) locus. Genes Immunity 2005, 6(1):53-65.

42. Shifman S, Kuypers J, Kokoris M, Yakir B, Darvasi A: Linkage disequilibrium patterns of the human genome across populations. Hum Mol Genet 2003, 12(7):771-776

43. Van Inghelandt D, Reif JC, Dhillon BS, Flament P, Melchinger AE: Extent and genome-wide distribution of linkage disequilibrium in commercial maize germplasm. Theor Appl Genet 2011, 123(1):11-20.

44. Boyko AR: The domestic dog: man's best friend in the genomic era. Genome Biol 2011, 12(2):216.

45. Laurie CC, Nickerson DA, Anderson AD, Weir BS, Livingston RJ, Dean MD, Smith KL, Schadt EE, Nachman MW: Linkage disequilibrium in wild mice. PLoS Genet 2007, 3(8):e144.

46. $R W, S P, E T, J H, K W, J B$ : Genomic selection using low density marker panels with application to a sire line in pigs. Genet Sel Evol 2013, 45:28.

47. Khatkar MS, Moser G, Hayes BJ, Raadsma HW: Strategies and utility of imputed SNP genotypes for genomic analysis in dairy cattle. BMC Genomics 2012, 13:538.

48. Finlay EK, Berry DP, Wickham B, Gormley EP, Bradley DG: A genome wide association scan of bovine tuberculosis susceptibility in Holstein-Friesian dairy cattle. PLoS One 2012, 7(2):e30545.

49. Kim BY, Jin HJ, Kim JY: Genome-wide association analysis of Sasang constitution in the Korean population. J Altern Complement Med 2012, 18(3):262-269.

50. He S, Liu H, Chen Y, Kuwahara M, Nakajima T, Zhong Y: Molecular phylogenetic relationships of Eastern Asian Cyprinidae (pisces: cypriniformes) inferred from cytochrome b sequences. Sci China C Life Sci 2004, 47(2):130-138.

51. He S, Mayden RL, Wang X, Wang W, Tang KL, Chen WJ, Chen Y: Molecular phylogenetics of the family Cyprinidae (Actinopterygii: Cypriniformes) as evidenced by sequence variation in the first intron of $\mathrm{S} 7$ ribosomal protein-coding gene: further evidence from a nuclear gene of the systematic chaos in the family. Mol Phylogenet Evol 2008, 46(3):818-829.

52. Wang X, Li J, He S: Molecular evidence for the monophyly of East Asian groups of Cyprinidae (Teleostei: Cypriniformes) derived from the nuclear recombination activating gene 2 sequences. Mol Phylogenet Evol 2007, 42(1):157-170.

53. Li H, Durbin R: Fast and accurate short read alignment with BurrowsWheeler transform. Bioinformatics 2009, 25(14):1754-1760.

54. Li H, Handsaker B, Wysoker A, Fennell T, Ruan J, Homer N, Marth G, Abecasis G, Durbin R: The Sequence Alignment/Map format and SAMtools. Bioinformatics 2009, 25(16):2078-2079.

55. Purcell S, Neale B, Todd-Brown K, Thomas L, Ferreira MA, Bender D, Maller J, Sklar P, de Bakker PI, Daly MJ, Sham PC: PLINK: a tool set for wholegenome association and population-based linkage analyses. Am J Hum Genet 2007, 81(3):559-575.

56. Boichard D, Chung H, Dassonneville R, David X, Eggen A, Fritz S, Gietzen KJ, Hayes BJ, Lawley CT, Sonstegard TS, Van Tassell CP, VanRaden PM, ViaudMartinez KA, Wiggans GR: Design of a bovine low-density SNP array optimized for imputation. PLoS One 2012, 7(3):e34130.

doi:10.1186/1471-2164-15-307

Cite this article as: Xu et al: Development and evaluation of the first high-throughput SNP array for common carp (Cyprinus carpio). BMC Genomics 2014 15:307.

\section{Submit your next manuscript to BioMed Central and take full advantage of:}

- Convenient online submission

- Thorough peer review

- No space constraints or color figure charges

- Immediate publication on acceptance

- Inclusion in PubMed, CAS, Scopus and Google Scholar

- Research which is freely available for redistribution

Submit your manuscript at www.biomedcentral.com/submit
C Biomed Central 